\title{
Ergonomics and Human Factors as a Requirement to Implement Safer Collaborative Robotic Workstations: A Literature Review
}

\author{
André Cardoso ${ }^{1}$, Ana Colim ${ }^{2}$ D , Estela Bicho ${ }^{1}\left(\mathbb{D}\right.$, Ana Cristina Braga ${ }^{1}\left(\mathbb{D}\right.$, Marino Menozzi $^{3}(\mathbb{D}$ \\ and Pedro Arezes $1, *$ (D) \\ 1 Algoritmi Centre, School of Engineering, University of Minho, 4800-058 Guimarães, Portugal; \\ andre.cardoso@dps.uminho.pt (A.C.); estela.bicho@dei.uminho.pt (E.B.); acb@dps.uminho.pt (A.C.B.) \\ DTx Colab, 4800-058 Guimarães, Portugal; ana.colim@dtx-colab.pt \\ 3 Department of Health Sciences and Technology, ETH Zurich, 8092 Zurich, Switzerland; mmenozzi@ethz.ch \\ * Correspondence: parezes@dps.uminho.pt
}

Citation: Cardoso, A.; Colim, A.; Bicho, E.; Braga, A.C.; Menozzi, M.; Arezes, P. Ergonomics and Human Factors as a Requirement to Implement Safer Collaborative Robotic Workstations: A Literature Review. Safety 2021, 7, 71. https:// doi.org/10.3390/safety7040071

Academic Editor: Tom Brijs

Received: 13 August 2021

Accepted: 8 October 2021

Published: 18 October 2021

Publisher's Note: MDPI stays neutra with regard to jurisdictional claims in published maps and institutional affiliations.

Copyright: (c) 2021 by the authors. Licensee MDPI, Basel, Switzerland. This article is an open access article distributed under the terms and conditions of the Creative Commons Attribution (CC BY) license (https:// creativecommons.org/licenses/by/ $4.0 /)$.

\begin{abstract}
There is a worldwide interest in implementing collaborative robots (Cobots) to reduce work-related Musculoskeletal Disorders (WMSD) risk. While prior work in this field has recognized the importance of considering Ergonomics \& Human Factors (E\&HF) in the design phase, most works tend to highlight workstations' improvements due to Human-Robot Collaboration (HRC). Based on a literature review, the current study summarises studies where E\&HF was considered a requirement rather than an output. In this article, the authors are interested in understanding the existing studies focused on Cobots' implementation with ergonomic requirements, and the methods applied to design safer collaborative workstations. This review was performed in four prominent publications databases: Scopus, Web of Science, Pubmed, and Google Scholar, searching for the keywords 'Collaborative robots' or 'Cobots' or 'HRC' and 'Ergonomics' or 'Human factors'. Based on the inclusion criterion, 20 articles were reviewed, and the main conclusions of each are provided. Additionally, the focus was given to the segmentation between studies considering E\&HF during the design phase of HRC systems and studies applying E\&HF in real-time on HRC systems. The results demonstrate the novelty of this topic, especially of the real-time applications of ergonomics as a requirement. Globally, the results of the reviewed studies showed the potential of E\&HF requirements integrated into HRC systems as a relevant input for reducing WMSD risk.
\end{abstract}

Keywords: physical ergonomics; cognitive ergonomics; ergonomic requirement; WMSD risk; cognitive workload; cobots; HRC

\section{Introduction}

The need to decrease the substantial costs and impacts on the life quality of workers, motivated by the occurrence of Musculoskeletal Disorders (WMSD), is leading to a growing awareness of reducing WMSD ratios in industrialized countries [1]. WMSD are the major health problem in developed countries [2], and WMSD have been an important cause for absenteeism and productivity loss in the manufacturing industry $[3,4]$. The annual incidence of these occupational disorders ranges between a quarter and a third of all occupational diseases [5]. WMSD are defined as a set of painful inflammatory and degenerative conditions affecting the joints, spinal discs, cartilage, muscles, tendons, ligaments, and peripheral nerves. The origin of these disorders is frequently associated with physical risk factors of manual handling such as repetitive movements of body parts, heavy lifting, and awkward postures [5].

A recently added solution for reducing WMSD is collaborative robots (Cobots) [4]. The European Union is contributing significantly to increase the effort in this field by recognizing Cobots as one of the technologies that can positively influence the economy and society [5]. Cobots have been developed to support human operators in the physical workload of manufacturing tasks with a certain degree of flexibility, using intuitive 
programming interfaces to accomplish that [6]. Therefore, they can improve the working conditions of operators by reducing WMSD [4]. For that reason, Human-Robot Collaboration (HRC) has been pointed to as a good solution when a task is physically demanding and too complex to be fully automated [2]. Since Cobots present systems to limit speed and forces, there is no need to physically cage these robots, and they can work alongside humans as co-workers [6,7]. This relationship positively impacts productivity, flexibility, and the creation of new jobs instead of replacing workers $[6,8]$. The previous referred studies demonstrated a link between Cobots and improved work conditions; however, the inclusion of ergonomic criteria in the development and implementation of these technologies is far from being well-known. In fact, the role of E\&HF on Cobots' systems design is an emergent research topic and a fundamental parameter in industrial engineering to improve the efficiency and effectiveness of industrial processes [9].

The developments in industrial HRC have focused primarily on technology development [10] and determining and minimizing safety risks [8]. The issue of safety in HRC is mainly related to collision avoidance, reactive motion planning techniques, and ensuring that the human user is safe from immediate injury due to any failure or error [7]. In addition to these mechanical risks, physical and mental strains can be added, since the operator may have to take inappropriate postures to deal with the robot's movements and, additionally, the operator moves up from a co-operant role to a position of supervising the work situation. This may lead to significant cognitive costs because of the allocation and reallocation of attentional resources [11]. Due to this, to achieve safer collaborative interactions between robots and human operators, it is needed to address the possible damage that may come due to the improper task execution or mental workload related to the introduction of these new technologies in the workstations [12], due to the use of more complex tasks or higher burden of cognition and decision making on the operator [13].

In order to accomplish the safest working conditions, E\&HF must be considered as a requirement in the implementation of collaborative systems [14]. E\&HF focuses on eliminating harmful and unsafe work practices in an industrial environment and aims to study human capabilities and limitations, and uses this knowledge to adapt the work to the worker while minimizing fatigue $[15,16]$.

Recently, a minor number of studies have considered the ergonomic benefits of integrating robots into task plans for human workers. Gualtieri et al. [9], in a literature review of the research challenges on ergonomics and safety in industrial HRC, pointed out the lack of studies on ergonomics compared to safety-related topics. Furthermore, the few studies concerned with occupational health aspects tend to present benefits on the working conditions as outcomes rather than factor the ergonomics criteria as requirements [17].

The inclusion of ergonomic requirements in industrial HRC is a prior need for successful implementations of this technology, foreseeing the reduction of WMSD occurrence systematically and improving the cognitive workload of operators. The role of E\&HF in HRC research seems to be addressed in two major ways: (i) offline, related to design and task allocation; and (ii) online, where a real-time assessment of the operator status can be performed, and a set of robotic actions can be performed by assisting the human to work in a more suitable configuration [12]. This designation (offline or online) will be used throughout the article, where offline applications include studies related to the design phase, and online applications include studies where a real-time assessment was performed.

In offline ergonomic applications, the ergonomic criteria are oriented towards workstation or Cobot mechanical design [18], where the central assumption is to combine the benefits of automation with the human workers' skills and cognitive flexibility $[6,12]$. Therefore, the tasks that require a high level of knowledge, individual decision-making, and complex movements are allocated to the human, and tasks with repeatability and fatigue proof are allocated to the robot $[19,20]$. However, offline applications are not suitable in industrial functions with fast-reconfigurability demands (such as dynamic task variation or human workers' limitations) since there is a need for real-time adjustments of 
the Cobots [21]. Hence, online ergonomic applications in HRC systems are being developed. These seem to be an innovative approach to dealing with the many issues of combining new technologies with human workers, putting the latter in the core role of the industrial workstations.

Online HRC applications are embedded with new instrumental-based tools for anticipating and evaluating human physical and cognitive states during work and setting appropriate robotic actions to deal with these. These instruments deal with an emerging issue: the worker assessment in dynamic environments. In addition to dealing with the improvement of the operator posture, these applications also care to provide the robot with the cognitive ability to communicate with the operator in real-time and make a job a true collaboration [22]. Ranavolo et al. [5] performed a literature review to investigate the need for revising the standards for human ergonomics and biomechanical risk assessment. The conclusions show that the need for revising these standards is mainly because of the use of innovative human augmentation technologies in the workplace, which makes traditional methods of WMSD risk assessment not applicable since they have relatively low reliability and cover only part of the workday [23].

Since mechanical hazards are not only what can harm an operator in HRC, also the lack of consideration of ergonomics as a requirement can lead to physical and cognitive stains. In this article, the authors are interested in understanding studies that included ergonomics as a requirement in HRC systems, giving particular attention to the segmentation between physical and cognitive ergonomics, and presenting an offline or online application. The major contribution of this paper is to sum up studies that have focused on the use of ergonomics to design safer collaborative workplaces and thus improve the well-being of workers.

\section{Method and Materials}

To achieve the proposed objective, a review of the literature was carried out, which, being replicable, also creates an operational base for future studies [24]. The Preferred Reporting of Items for Systematic Reviews and Meta-Analyses (PRISMA) [25] methodology is the basis of a whole new vision for developing literature reviews since 2009 [26]. This methodology supported this review to ensure comprehensive, transparent, and impartial reporting. Four of the leading bibliographic databases were used to find relevant papers published in the field of the research, namely Scopus, Web of Science, PubMed, and Google Scholar. The use of these electronic databases for the keyword search is justified by the fact that they are the most relevant for publications in the engineering and manufacturing area [9].

As a condition of inclusion, the articles had to be written in English and published between 2001 and 2021. A total of 434 scientific articles were obtained after searching with the keywords 'Collaborative robots' or 'Cobots' or 'HRC' and 'Ergonomics' or 'Human Factors'. The combination of one of the first three keywords with the last two was achieved with the Boolean operator 'AND'. The authors' database was also considered in this literature review. After eliminating repeated articles, a total of 201 articles were obtained. Only articles that presented ergonomics as a requirement in HRC systems were selected. For this purpose, the tracking was undertaken through the titles and abstracts of these. When the abstracts did not provide enough information to decide, a complete reading of the article was performed. To help conduct the analysis, a table was built to collect from each paper the most relevant information regarding the study aims. In addition, elements such as authors' identification (name), year of publication, study objectives, main results, metrics, tools utilized, the country in which the study took place, sample, the context of the study, ergonomic type (physical or cognitive), and application (online or offline) were collected.

The articles obtained were analyzed and summarized to present a general characterization of HRC systems where ergonomics was included as a requirement, giving special 
attention if the study was related to physical or cognitive ergonomics and if presented an offline or online application.

\section{Results and Discussion}

The search resulted in 434 potentially eligible studies, of which 201 were duplicates, and 116 were excluded based on the review of the titles and abstracts. An additional 26 studies were excluded after not being available in full-text and 31 after reviewing the full-text, leaving 22 studies (Figure 1) for data collection. The small number of studies reveals the novelty of ergonomics as a requirement in HRC systems. This statement is further sustained by the other findings that are next presented.
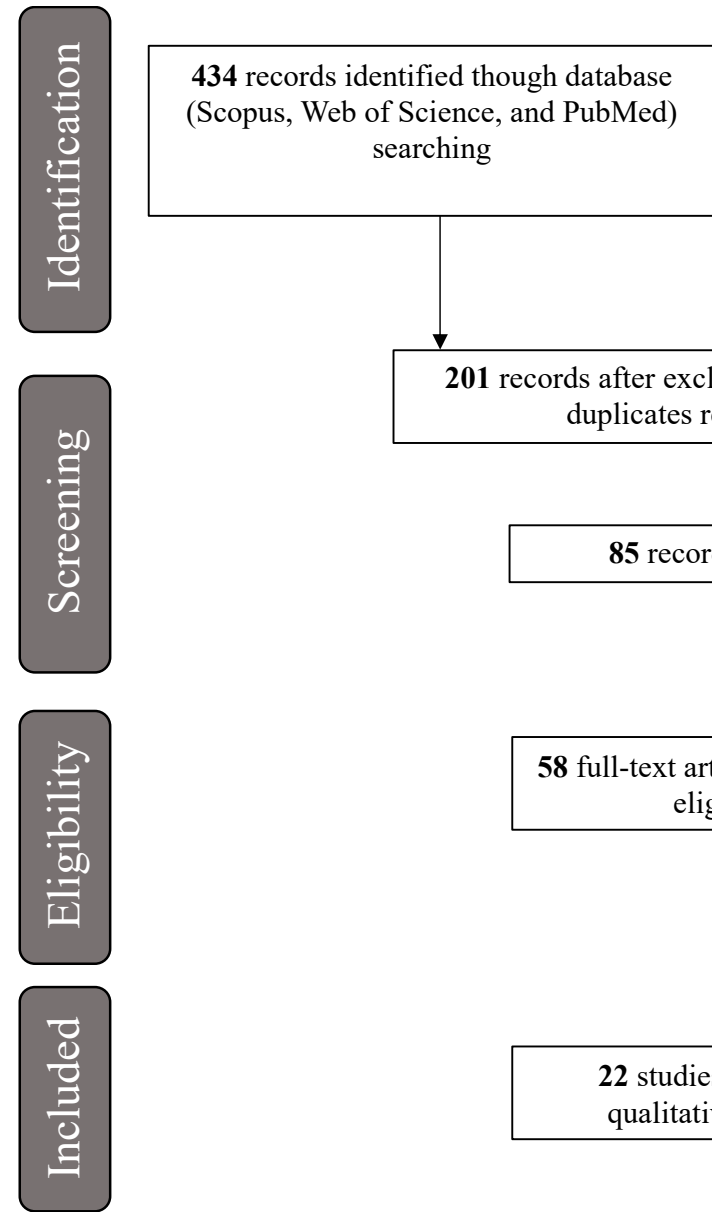

$\mathbf{1}$ additional record identified though other sources
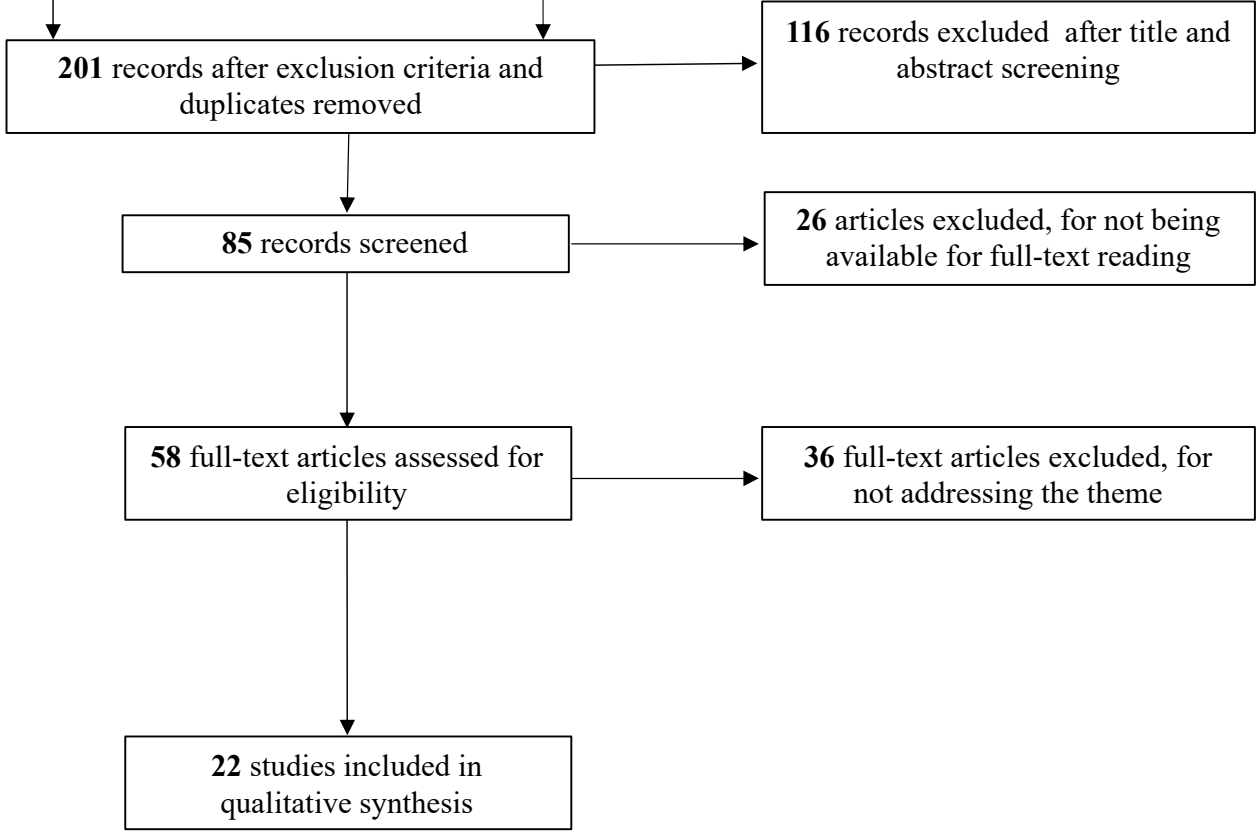

available for full-text reading

Figure 1. Steps of the PRISMA protocol for the literature review on E\&HF in HRC.

This review allows us to know the distribution of works related to ergonomics as a requirement around the world. Figure 2 shows the number of articles per country. Our results allow us to say that the country where more studies have been developed in this field is Italy [1,12,27-33], followed by the USA [8,34], United Kingdom [18,35], France [11,31], and Greece $[22,36]$. In the rest of the countries, only one study per country was found. 


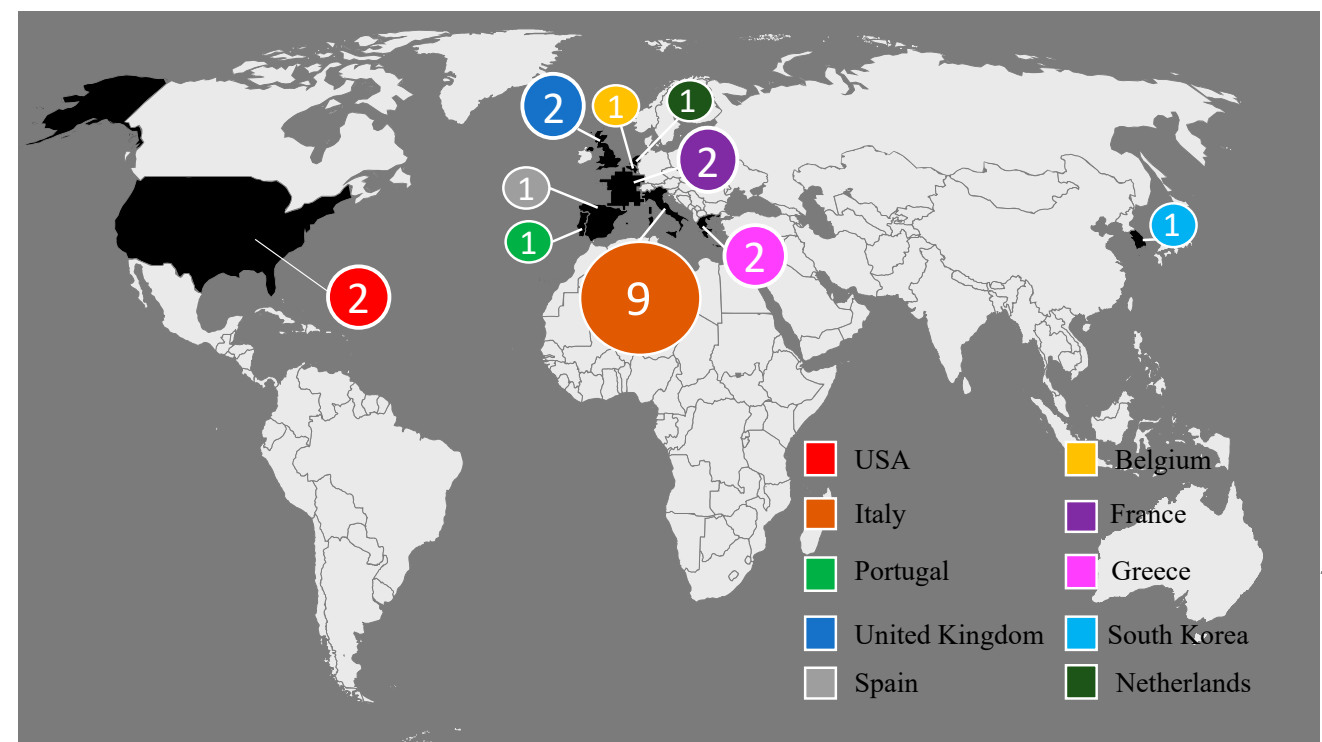

Figure 2. The number of articles per country reporting about E\&HF in HRC.

Regarding the year of publication, our study shows that the oldest paper presented in this review dates to 2013 [31] (Figure 3). Moreover, the largest number of studies found have been published in 2021 [11,12,19,22,27,32,33,37,38]. These two findings point out that E\&HF as a requirement in HRC systems is an emergent/recent research topic. In fact, Gualtieri et al. [9] addressed a review on emerging research fields in safety and ergonomics in industrial collaborative robotics, which underwent a period from 2015 to 2018, and concluded that ergonomics has been only growing significantly in the last two years of the mentioned period.

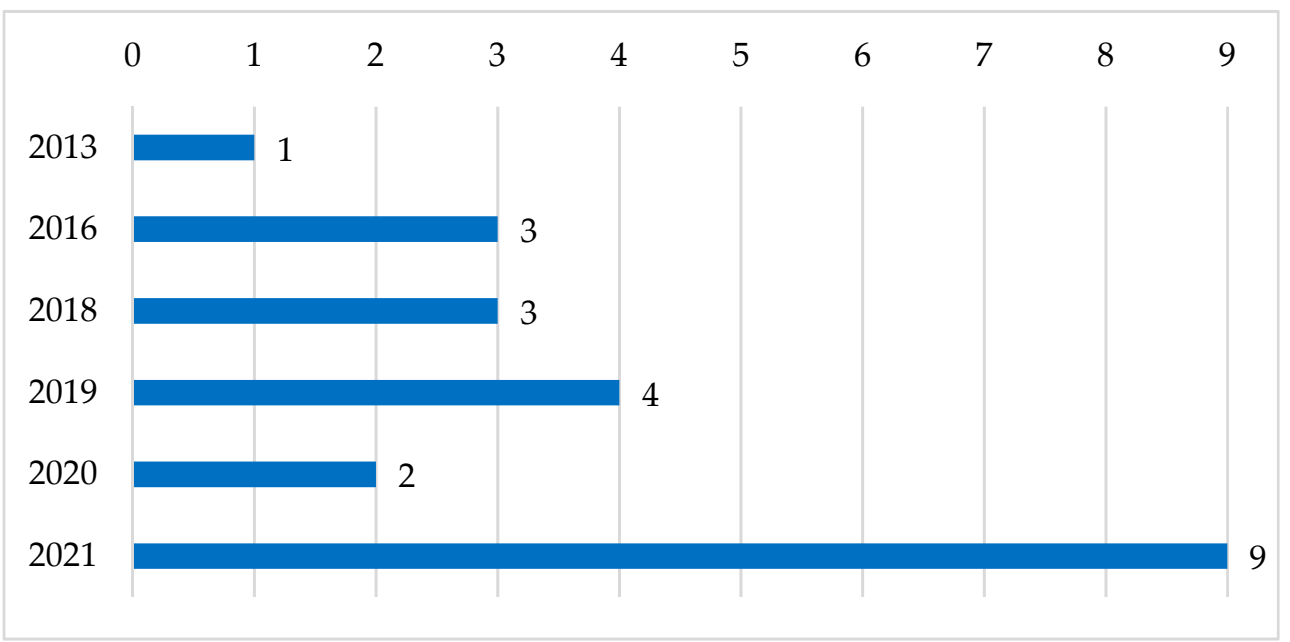

Figure 3. Articles distribution per year.

Another finding that denotes this research field's novelty is that most of the studies have been performed in a laboratory environment (Figure 4). Only five articles presented a study in a real-industry context; two of them are related to physical ergonomics $[8,19]$, and three to cognitive ergonomics $[11,33,38]$. This evidence is sustained by the fact that innovative research fields start from laboratory context and then are exploited to realworld context [39]. Regarding the Virtual Simulation context, five studies $[16,30,31,36,37]$ were found, all of them related to physical ergonomics. This kind of context seems to be very appropriate for considering ergonomics requirements when designing and testing HRC configurations since it provides the opportunity to evaluate the feasibility of the process through different scenarios. Additionally, these types of context are proven to 
appreciably reduce the time and cost of product development $[30,31,37]$. Related to this, three papers were found in which workstations were studied in a virtual environment. Hedaryan et al. [30] used the software Tecnomatix Process Simulate to model an assembly workstation, and Pini et al. [16] used the simulation tool DELIMA for ergonomic analysis of the HRC. Ottogalli et al. [37] proposed a Virtual Reality simulator to perform and evaluate multiple design assembly processes and assess the worker's ergonomics. This kind of simulation environment has many advantages in the design of collaborative workstations, especially when one intends to consider ergonomic requirements. The major advantage that can be mentioned is that it allows the capability to study the ergonomics of the human worker while assembling the parts and coexisting with robots, without compromising the worker's safety [37]. Related to theoretical context, there was found only one study [35].

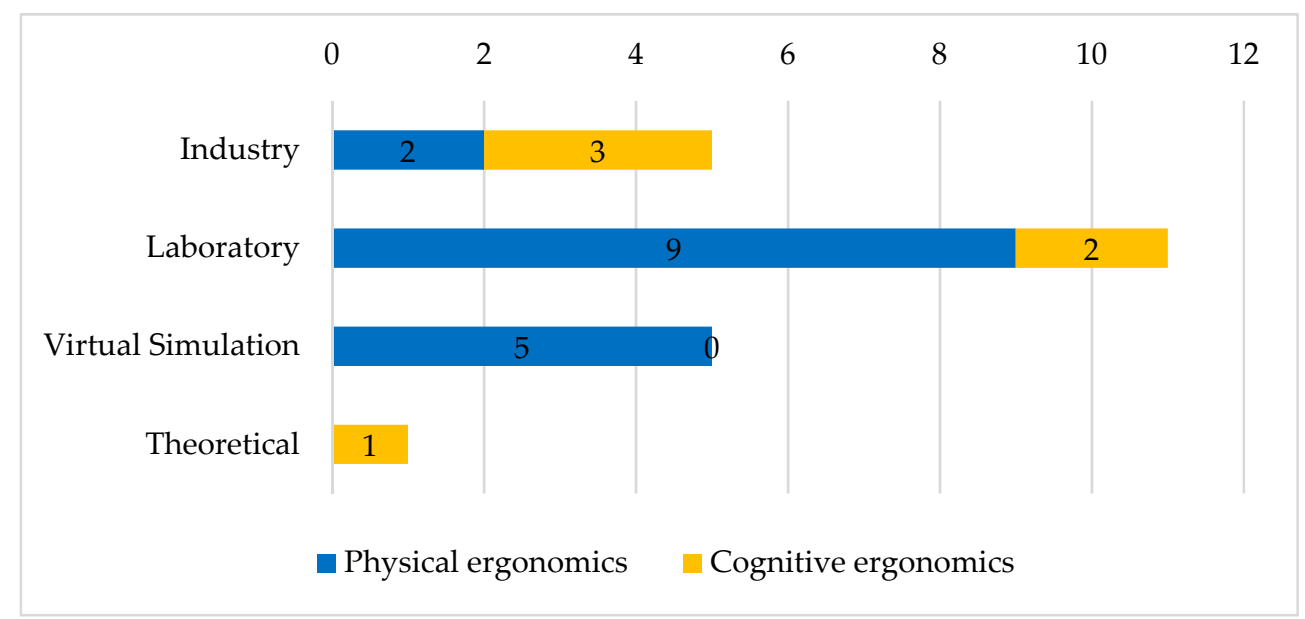

Figure 4. Articles distribution per context (industry, laboratory, virtual simulation, or theoretical) related to the ergonomics domain (physical or cognitive).

Another finding from our study is related to the ergonomics domain, namely physical or cognitive, and related to its ergonomic application, if offline or online (Figure 5). Sixteen $[1,4,7,8,13,17,19,22,27-31,36,37,40]$ of nineteen studies are related to physical ergonomics, while only six $[11,32,34,35]$ are related to cognitive ergonomics. Regarding its application, only studies related to physical ergonomics presented an online application $[1,12,18,22,33,38,40]$. These studies, in which an online application was implemented, aim for workers' postural improvement by modifying the Cobot's behaviour to bring the human operator to a more ergonomic body configuration. The robot's awareness of the human counterpart posture was acquired through wearable sensors $[1,12,40]$ or vision-based systems [18,22]. The studies that implement physical ergonomic requirements in offline applications seem to address task allocation issues $[4,8,30,36]$ or design and assessment of HRC solutions [16,19,27-29,31,37].

Finally, related to the application (online or offline), it has been shown that only $22.7 \%$ of the studies reviewed presented an online application of ergonomics where Cobots assume different actions according to the health state of workers while performing a determined task. This result points out that the online ergonomic requirement in HRC systems is less addressed than the offline ergonomic requirement, suggesting that it is even more in an embryonic stage. 


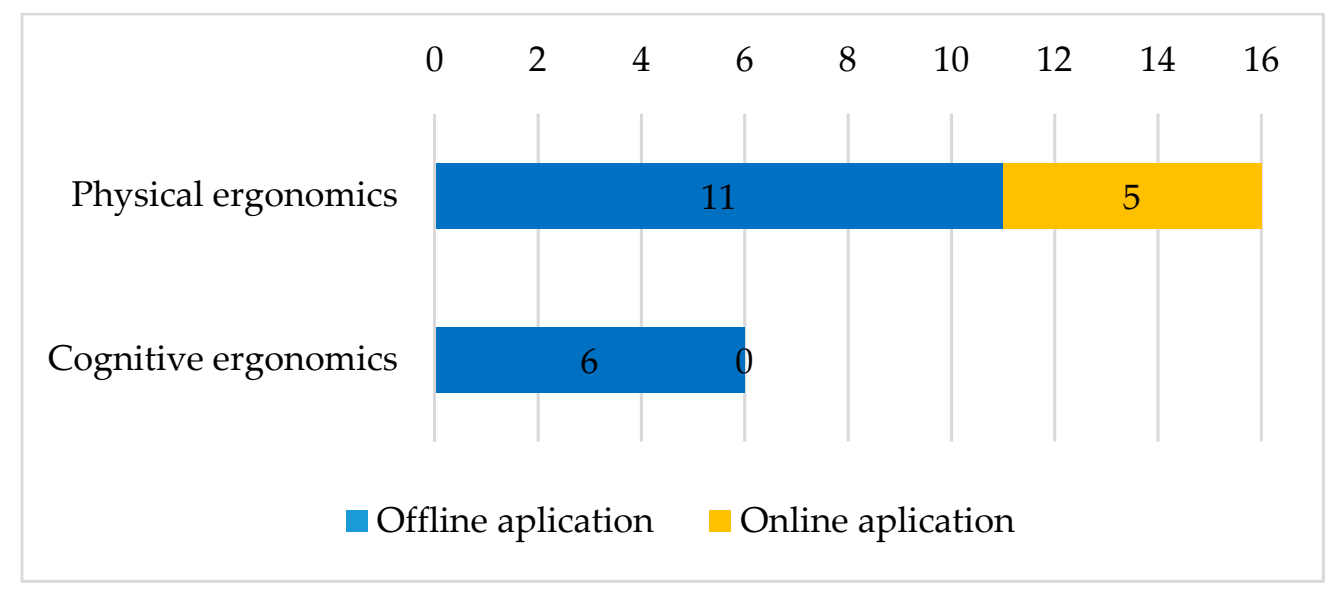

Figure 5. Articles distribution per type of ergonomics (physical or cognitive) related to its ergonomic application (offline or online).

\subsection{Physical Ergonomics}

Physical ergonomics is concerned with human anatomy, anthropometric, physiological, and biomechanical characteristics as they relate to physical activity. In this sub-field of ergonomics, relevant topics include working postures, materials handling, repetitive movements, WMSD, workplace layout, and safety and health [41]. Specifically, in HRC systems, physical ergonomics deals with the principles of reducing biomechanical workload by using Cobots to improve operator physical well-being and improve system performance [9]. Table 1 presents the summary of the reviewed studies related to physical ergonomics. It presents the aim, the number of subjects in the experimental setup, and the main results of each study. Some studies showed the digital transformation of a manual workstation into a collaborative one $[16,19,27,28]$. These studies rely on assessing the manual workstation through ergonomic tools to define the ones that cause more physical strains. Once this assessment is finished, the design of the collaborative workstation can be performed, considering the decrease in WMSD risk factors of the different tasks considered. Other studies showed the approach for allocating tasks either to the human operator or the Cobot $[4,8,30,36]$. These approaches are algorithm-based, among others, rely on ergonomic considerations to allocate a task to each collaborative counterpart. One other study assessed the ergonomic benefits of selecting different Cobots for a determined task [31]. In this study, the authors compared the benefits of two robots with different conformations in a simulated scenario, aiming to conclude which of the robots conferred a greater improvement in the worker's posture. Another study showed the implementation of an end-effector to handle large working pieces [29]. In this study, a control strategy was implemented in the robotic manipulator to minimize the muscular fatigue of the operator since the robot became able to move the workpiece, ensuring that the human operator is always close to his most natural posture. All the referred studies have an offline application of ergonomic requirements. Related to online applications, the studies reviewed aimed at improving operator posture in real-time $[1,12,18,22,40]$. These studies rely on instrument-based systems to assess the physical state of the operator. According to deviations from the neutral posture, the robot is trigged to change its behaviour, leading the operator to take a more ergonomic posture in real-time. 
Table 1. Summary of the reviewed studies related to physical ergonomics (presented in chronological order of publication).

* denotes studies with online applications.

\begin{tabular}{llll}
\hline \multicolumn{1}{c}{ Authors and Year } & \multicolumn{1}{c}{ Objective } & Subjects & \multicolumn{1}{c}{ Main Results } \\
\hline (Colim et al., 2021) [19] & $\begin{array}{l}\text { Assessment of industrial implementation } \\
\text { of a collaborative robotic workstation for } \\
\text { assembly tasks. }\end{array}$ & $n=4$ & $\begin{array}{l}\text { WMSD risk decrease in all performed } \\
\text { observational methods in the collaborative } \\
\text { workstation. }\end{array}$ \\
\hline & $\begin{array}{l}\text { Description of technical realization of a } \\
\text { collaborative workstation developed for } \\
\text { a real-industry case study. }\end{array}$ & $n=1$ & $\begin{array}{l}\text { Improvement of working conditions, since } \\
\text { Rapid Upper Limb Assessment (RULA) } \\
\text { results, showed a reduction of 50\% for the } \\
\text { left part of the body and 57\% for the right } \\
\text { part of the body when compared with the } \\
\text { manual workstation. }\end{array}$ \\
\hline & $\begin{array}{l}\text { Development of Virtual Reality } \\
\text { simulation environment to address } \\
\text { performance and worker ergonomics. }\end{array}$ & N.A. & $\begin{array}{l}\text { The results show that most of the new } \\
\text { proposed strategies improve the assembly } \\
\text { time, worker cost, or ergonomics of the } \\
\text { process. }\end{array}$ \\
\hline
\end{tabular}

Development of an AI-based system that

can capture the operator and

(Dimitropoulos et al., 2021) environment status and provide

$[22]^{*}$

\section{customized operator support from the}

robot side for shared tasks, automatically

adapting to the operator's needs

and preferences

Development of novel HRC control method that can guide human

(Kim et al., 2021) [12] * co-workers to more ergonomic working $n=10$ configurations during dexterous operations.

Design of a collaborative workstation to improve the operators' physical ergonomics while keeping or increasing the level of productivity.

(Gualtieri et al., 2020) [28]

Development and validation of a

(Liau \& Ryu, 2020) [36]

framework for task allocation for a workstation composed of one human and two collaborative robots.

N.A.

$n=2$

$n=2$

Muscle arm activity in some tested configurations resulted in the lower effort. This approach only considered muscles of the arm.

\section{Improvement of conditions in terms of} manual handlings. The overall Occupational Repetitive Actions (OCRA) and RULA values were reduced.

The average RULA score for the manual operation was 4.54. The introduction of two robot collaboration in the operation reduced the WMSD risk level on the human to 2.31 .

(Shafti et al., 2020) [18] * Development and validation of a novel approach in HRC driven by ergonomics.

$n=5$ Successful real-time robot-aided posture improvement.

Development of a whole-body and subject-specific model to identify an

(Lorenzini et al., 2019) [1] * individual's fatigue progression over time while performing repetitive tasks involving light payloads. When fatigue excessed a threshold in any joint, a body posture optimization was triggered, guided by the collaborative robot assistance, and the accumulation of further fatigue was thus avoided

Development of a motion control algorithm for a robotic manipulator to perform the gross of the motion, thus (Zanchettin et al., 2019) [29] limiting the amplitude and the range of motion of the operator to perform an achieved task.

(Makrini et al., 2019) [4]
Development of a framework for task allocation in HRC assembly.
Lower exposition to WMSD and, in turn, $n=19$ no substantial modification in the quality of the production.
N.A.
The physical workload is set at the desired level. 
Table 1. Cont.

\begin{tabular}{|c|c|c|c|}
\hline Authors and Year & Objective & Subjects & Main Results \\
\hline (Pearce et al., 2018) [8] & $\begin{array}{l}\text { Presentation of a framework for agent } \\
\text { allocation (human or robot) minimizing } \\
\text { task completion time and human } \\
\text { physical "strain." }\end{array}$ & $n=6$ & $\begin{array}{l}\text { Improvement of physical stress in some } \\
\text { tasks. The best results happen for tasks } \\
\text { where parallel work is enabled. }\end{array}$ \\
\hline (Heydaryan et al., 2018) [30] & $\begin{array}{l}\text { Development of human-robot } \\
\text { collaboration workstation for the case of } \\
\text { an automotive brake disc assembly }\end{array}$ & N.A. & $\begin{array}{l}\text { HRC solution improves human ergonomics } \\
\text { considerably and reduces the operator } \\
\text { injury risk. }\end{array}$ \\
\hline (Kim et al., 2018) [40] * & $\begin{array}{l}\text { Development of a real-time technique for } \\
\text { reducing the overloading joint torque in } \\
\text { humans while performing heavy } \\
\text { manipulation tasks with robots. }\end{array}$ & $n=1$ & $\begin{array}{l}\text { Reduction of the shoulder and elbow joint } \\
\text { torques in } 40 \% \text { to } 50 \% \text { more when } \\
\text { compared to an initial experiment in which } \\
\text { the robot trajectories were not optimized } \\
\text { along the x-axis. }\end{array}$ \\
\hline (Pini et al., 2016) [16] & $\begin{array}{l}\text { Development of an approach to evaluate } \\
\text { the operator relief, based on a modified } \\
\text { model for the fatigue evaluation. }\end{array}$ & N.A. & $\begin{array}{l}\text { Reduction of RULA scores for the HRC } \\
\text { solution. Reduction of fatigue level of the } \\
\text { operator in } 42 \% \text { when compared to the } \\
\text { manual situation. }\end{array}$ \\
\hline (Maurice et al., 2013) [31] & $\begin{array}{l}\text { Development of a dynamic simulation } \\
\text { framework to model the performing of a } \\
\text { task jointly by a virtual manikin and } \\
\text { a robot. }\end{array}$ & N.A. & $\begin{array}{l}\text { One of the robots induces a significant } \\
\text { decrease in the manikin efforts. The other } \\
\text { one leads to a situation that is worse than } \\
\text { without assistance. }\end{array}$ \\
\hline
\end{tabular}

Overall, all studies showed its effectiveness in improving working conditions by considering ergonomic requirements in the process of digital transformation of manual workstations.

The ergonomic metrics used in some of the reviewed (Figure 6) studies still rely on observational methods in a traditional way. Ergonomic experts apply these methods through direct observation of the work activity to perform a risk assessment. They consider risk factors related to the occurrence of WMSD and assess the impact of these risks based on the external physical workload $[42,43]$. In the reviewed studies, the following observational methods were applied: RULA [19,27,28], OCRA [28], Key Indicator Method for Manual Handling Operations (KIM-MHO) [19], and Strain Index (SI) [8,19]. Notwithstanding, some studies already presented an adaptation to the traditional way of application of these tools. For instance, Liau \& Ryu [36] and Pini et al. [16] applied RULA in a virtual scenario, using simulation software that allowed the application of this observational tool. Shafti et al. [18] and Dimitropoulos et al. [22] applied RULA. Its application is based on a vision tracking system of the human body, incorporated in the Cobot, which relies on an algorithm to calculate the final RULA score in real-time. Makrini et al. [4] applied an adaptation of Rapid Entire Body Assessment (REBA). In addition, Ottogalli et al. [37] applied Ovako Working posture Analysis System (OWAS) in a Virtual Reality scenario to assess the posture and its frequency. Vega-Barbas et al. [23] argue that real-time kinematic data helps to improve traditional assessment methods such as RULA and REBA that are mainly based on visual observations. 


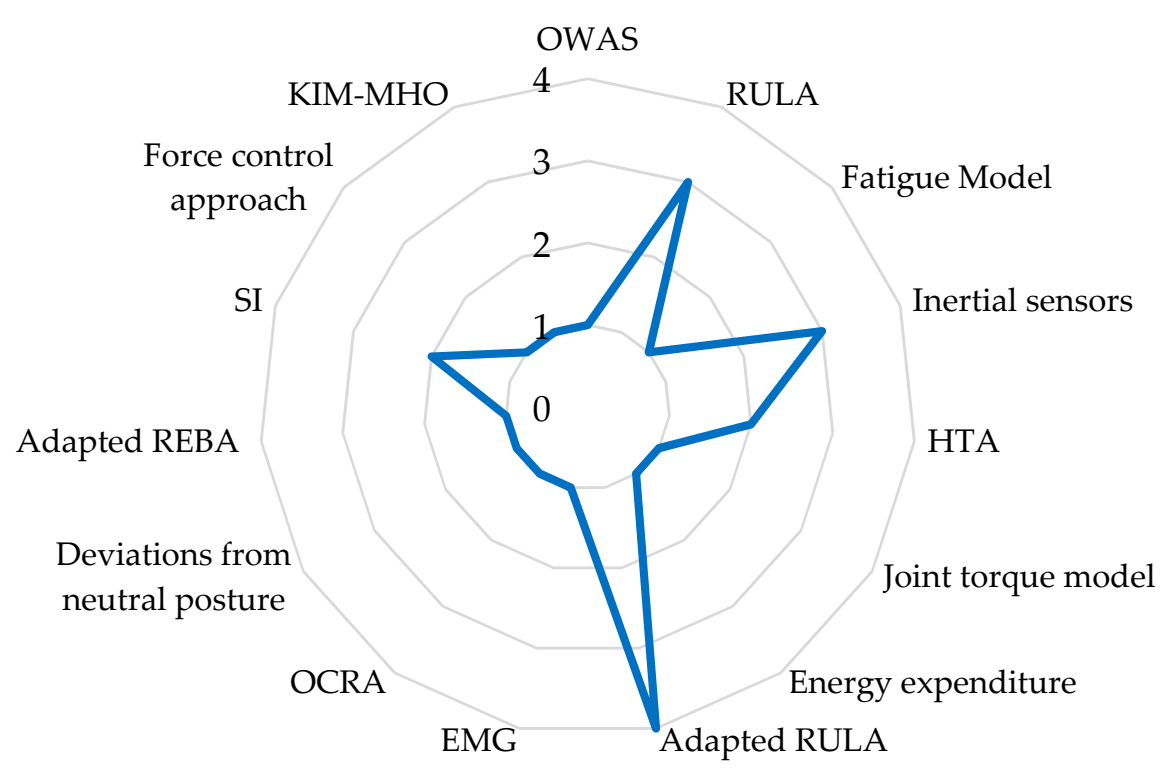

Figure 6. Distribution of physical ergonomics assessment methods used in the reviewed studies.

Additionally, some reviewed studies applied direct measurement ergonomic methods. These methods rely on sensors attached to the workers' body to directly measure risk factors' effect on physical and biomechanical parameters [37,38]. Kim et al. [12] applied surface electromyography (EMG) and Lorenzini et al. [1] and Kim et al. [12,40] used inertial sensors to estimate the position of the body joints.

Algorithm-based ergonomic methods were also applied. For example, Lorenzini et al. [1] applied an overload fatigue model that estimates the progression of fatigue by taking into account two major factors: the variability of the overloading on the joints in the presence of an external force and an individual's subjective perception of fatigue. Kim et al. [40] applied a dynamic model of the human body to define the relationship between the centre of pressure and the interaction forces to estimate the overloading human joint torque. Zanchettin et al. [29] assessed the deviations from the neutral posture of the arm through the vision system, based on skeletal points, and specifically using the information about the position of the feet in the $x y$-plane. Finally, Maurice et al. [31] applied a force control approach based on a quadratic programming problem that relies on the centre of mass, contact forces, and the posture of the human body.

In our review, other methods were found. An example of that is Energy Expenditure, where energy is evaluated through the consumption of oxygen which is related to a metabolic cost [16], and Hierarchical Task Analysis (HTA) used for decomposing human tasks, regarding different ergonomics and human factors [8,30].

Our results show that the physical ergonomic tool more utilized in the context of HRC was the adaption of RULA (four studies). This RULA adaption allows to measure the physical workload during the entire workday. The second most used tool was the RULA (applied in the traditional way). With the same number of references (three studies), there is the application of inertial sensors. SI and HTA were applied in only two studies. All the other tools were applied in only one study each.

\subsection{Cognitive Ergonomics}

Cognitive ergonomics is concerned with mental processes, such as perception, memory, reasoning, and motor response, as they affect interactions among humans and other system elements. This ergonomics domain includes relevant topics, such as mental workload, decision-making, skilled performance, human-computer interaction, human reliability, work stress, and training, as these may relate to human-system design [41]. In HRC 
systems, cognitive ergonomics deals with interaction acceptability by minimizing mental stress provided to operators when sharing workspaces with Cobots [9]. Table 2 presents a summary of the reviewed studies related to cognitive ergonomics. It presents the aim, the number of subjects in the experimental setup, and the main results of each study. The studies where a cognitive ergonomic requirement was considered can be divided into two major topics: assessing the impact of a collaborative workstation on the wellbeing of workers [12,32] and developing a framework for a trust-based integrated scheme for HRC $[34,35]$. The studies in the first topic aim to investigate the consequences on operators of a shared workplace with a Cobot, while the studies in the second topic aim to implement HRC solutions based on cognitive workload improvement. The results of the reviewed studies show that most of the workers agreed that Cobots can improve working conditions through the support given by this technology, which reduces stress caused by industrial tasks. Additionally, the results of the reviewed studies also point out that the integration of trust-based approaches allows for decreasing perceived task load, leading to a better collaboration of the two elements of the collaborative systems. It is important to note that one of the critical elements of HRC for effective collaboration is trust. This key element determines humans' use of autonomy, and improper trust can lead to either over-reliance or under-reliance on the robot, and thus an increased task load and reduced task performance [34].

Related to cognitive ergonomic tools (Figure 7), our findings indicate that the most used were NASA-Task Load Index (NASA-TLX) [32,34] and interviews [11,38]. The other tools were applied only in one study each. NASA-TLX was used for assessing the task load [32,34]. Technology Acceptance Model (TAM) questionnaire was used to assess Cobot acceptance. This questionnaire has a revised version appropriate for evaluating the robot's acceptance [32]. System Usability Scale (SUS) was applied to assess the usability of the HRC system [32]. The study of Brun \& Wioland [11] used interviews to assess the operator's activity and feelings. In addition, Lambrechts et al. [38] used interviews to identify human factors in the Cobot implementation process, resistance to change, and leadership during Cobot implementation. Some of the human factors found were communication, resistance to change, and culture. Human Trust in Automation Questionnaire (HTAQ) was applied to assess the operator's trust in his robot teammate [34]. All tools mentioned above are based on subjective measures.

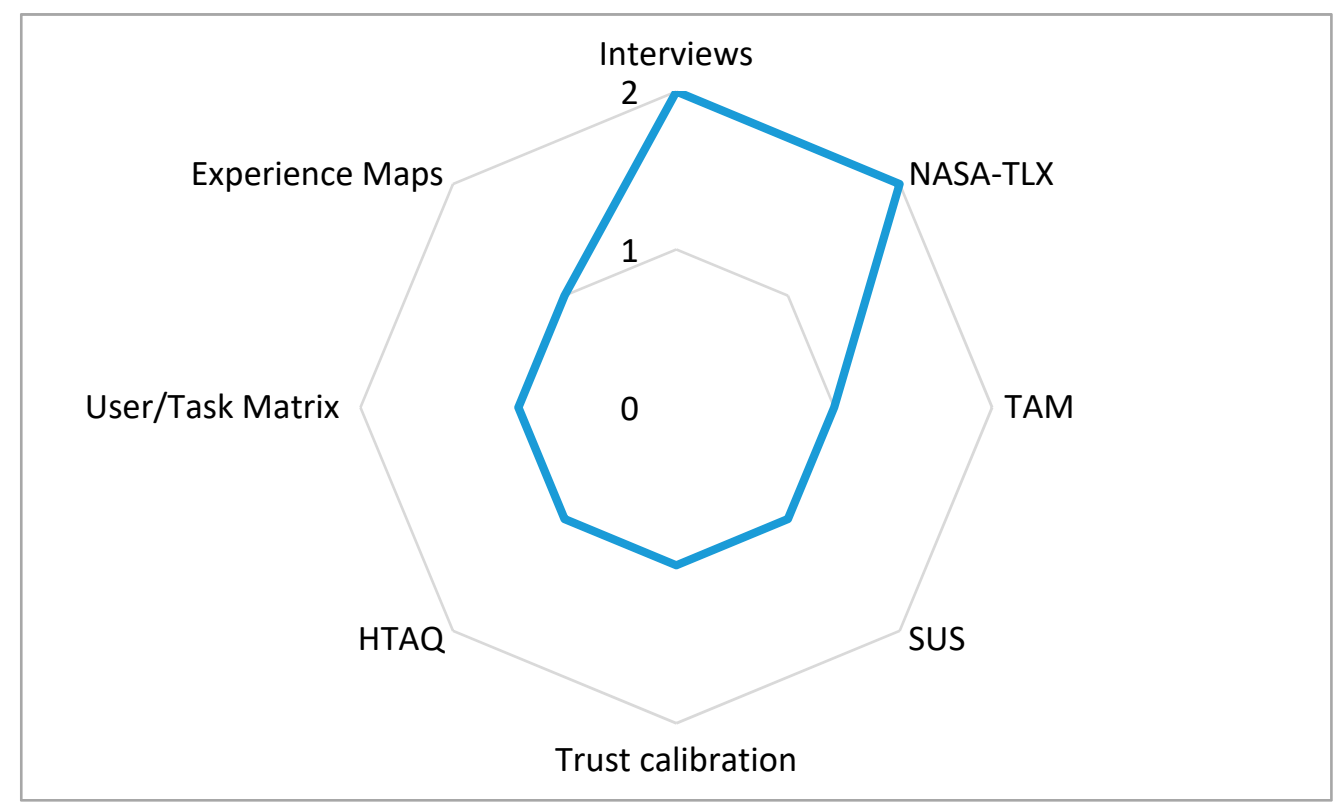

Figure 7. Distribution of cognitive ergonomics assessment tools used in the reviewed studies. 
Table 2. Summary of the reviewed studies related to cognitive ergonomics (presented in chronological order of publication).

\begin{tabular}{|c|c|c|c|}
\hline Authors & Objective & Subjects & Main Results \\
\hline (Brun \& Wioland, 2021) [11] & $\begin{array}{l}\text { Investigation of the consequences of } \\
\text { Human-Robot Collaboration on the } \\
\text { operator's activity and his feelings }\end{array}$ & $n=8$ & $\begin{array}{l}\text { All workers agreed that the collaborative } \\
\text { system impacts the organization. Most of } \\
\text { the workers }(75 \%) \text {, also agreed that the } \\
\text { implementation of collaborative robots } \\
\text { improves working conditions and } \\
\text { confidence, gives support and relief and } \\
\text { decreases stress and fatigue. }\end{array}$ \\
\hline
\end{tabular}

The results demonstrate the importance of

Investigation of implementation the

(Lambrechts et al., 2021) [38] influence of human factors on the implementation of Cobots in planning the Cobots implementation assembly lines.

$n=4$ process in phases, since employees are hesitant or resistant to the change due to a lack of information, experience, and communication.

Investigation of the extent to which users' age (i.e., adults, senior workers) and cobot control modality (i.e., manual, tablet) affect the acceptance, UX, usability, and task load related to cobot usage.
Workers of different ages viewed the Cobot not as a replacement but as a supportive $n=20 \quad$ and independent "colleague" who is pleasant, attractive, and satisfying to interact with.
Development a user experience (UX)-oriented structured method to

(Prati et al., 2021) [33] investigate the human-robot dialogue to map the interaction with robots during the execution of shared tasks.
Results demonstrated the validity of the proposed tools to understand the human-robot interaction, describe the communication issues, and define the main interface features to support the following interface design activity.

The roadmap provides propositions in a guiding framework for practitioners to

Development of Human Factors roadmap for the successful implementation of industrial HRC.
N.A. assist appropriate trust calibration to the robotic teammate, through a Training programme and Operator empowerment.

The human-perceived task load is lowest in the trust-based integrated framework. Comparison of human perceived task load and subjective trust in the robot reveals that the human worker experiences a better collaboration during the trust-based integrated scheme. $n=5$
(Sadrfaridpour et al., 2016) [34]
Development of a trust-based integrated scheme for HRC in manufacturing to take into account human-in-the-loop considerations at the psychological levels.

Another tool found was trust calibration. This tool relies on: (i) a training program that will enable operators to understand the abilities as well as limitations of the robotic teammate, which will allow human operators to develop an appropriate, and more realistic, mental model of the robot they will be requested to collaborate with; and (ii) operator empowerment through the experience of collaborating with the robotic teammate to enhance his ability during degraded events, such as robot failures, errors, or deviations [35].

The User/Task Matrix and Experience Maps are tools proposed by Prati et al. [33] oriented to user experience. The User/Task Matrix is appropriate for registering an interaction scenario between human workers and robots. Examples of this include tasks' duration, actors, communication, cycle time, critical situations, possible solutions, and working conditions. The registration of the above-mentioned parameters should allow for understanding of the frequency of human-robot interactions, how complex they are, and how long they take. Experience maps represent a synthetic visualization of an entire endto-end experience that a worker goes through to accomplish a certain task in collaboration with a robot. These also allow understanding human behaviour and further assist in the interaction design process between humans and robots. 
The results point to the fact that cognitive ergonomics techniques are diversified. To the best of the authors' knowledge, there is not yet a framework to follow in this matter.

\section{Conclusions and Future Work}

The increasing customer demand for customized products puts pressure on companies to improve flexibility in their production systems. As the use of automation always helped improve production systems' capacity, it is expected to achieve similar results after the implementation of Cobots in the industry [15]. It is also expected that implementing these technologies helps eliminate risk factors and, therefore, improves working conditions.

Regardless of the specific task performed, robots are designed to support humans. Consequently, by introducing Cobots into workstations, it is necessary to consider ergonomic requirements in their implementation. Thus, it is not possible to speak of robots without considering them in relation to humans. Adopting the human's point of view allows one to foresee the user's needs, behaviour, and sensations during the interaction with robots and improve workers' physical well-being and safety [33]. Previous studies recognized the importance of considering E\&HF in task allocation and planning for human-robot teams.

The literature focuses primarily on the ergonomic outcomes of integrating robots in workplaces [10]. The current work aimed to review studies that present ergonomics as a requirement in HRC systems rather than an outcome. This work provides key information for further investigations on the topic. The results show that this field is an emergent research topic. Most of the studies presented an offline application of ergonomic principles or methods. These are not adequate for optimizing ergonomic criteria in dynamic humanrobot collaboration tasks. Online methods are still in a seminal state, but the few studies with online applications showed their effectiveness in reducing WMSD risk. Moreover, online applications seem to be a great asset to include workers with disabilities since the robot assistant can, e.g., adjust its end-effector according to the worker's pose in the most ergonomic posture.

Globally, all the studies reviewed demonstrated the importance of the role of E\&HF as a requirement in HRC systems' design and implementation since the results prove the improvement of working conditions in terms of physical and cognitive strains. However, most of the studies focused on specific situations or tasks that do not allow generalization of the results for all the different situations encountered in the industrial context.

From a cognitive ergonomics perspective, the execution of time-sharing activities frequently increases overall cognitive workload. A higher level of cognitive workload on humans has adverse effects on performance, work quality, Cobot acceptance, and on the overall mental wellbeing of human operators [6]. Since all studies focused mainly on physical ergonomics, future research should also focus on cognitive ergonomics, and especially with online applications. The implementation of new technologies in the workplace can increase the mental workload [13]. Furthermore, there seems to be a great diversity of ergonomic methods and techniques to be used, with no consensus on which will be more appropriate in this new context in which humans interact with Cobots during their working day.

Based on the obtained results, and since there is no well-established methodology or even commonly accepted metrics, the authors believe that further research should first focus on creating a comprehensive framework that allows the assessment of cognitive and physical workload. More research will have to be carried out at this level, and this work will set the tone for future investigations. Another equally important line of research will be implementing and improving online applications of physical and cognitive ergonomic requirements. The adaptation of Cobot behaviour according to worker status is a primordial asset to develop safer workstations and improve workers' well-being.

Author Contributions: A.C. (André Cardoso): conceptualization, methodology, investigation, writing, review and validation; A.C. (Ana Colim): conceptualization, writing, review, validation and supervision; E.B.: investigation support, validation, supervision and review; A.C.B.: investigation 
support, validation and supervision; M.M.: validation and review; P.A.: validation and review. All authors have read and agreed to the published version of the manuscript.

Funding: This work has been supported by FCT-Fundação para a Ciência e Tecnologia and MIT Portugal Program under the doctoral Grant SFRH/BD/151365/2021. This work has been also supported by NORTE-06-3559-FSE-000018, integrated in the invitation NORTE-59-2018-41, aiming the Hiring of Highly Qualified Human Resources, co-financed by the Regional Operational Programme of the North 2020, thematic area of Competitiveness and Employment, through the European Social Fund. Additionally, has been also supported by FCT within the Project "I-CATER-Intelligent robotic Coworker Assistant for industrial Tasks with an Ergonomics Rationale", Ref. PTDC/EEIROB/3488/2021, and within R\&D Units Project Scope: UIDB/00319/2020.

Conflicts of Interest: The authors declare no conflict of interest. The funders had no role in the design of the study; in the collection, analyses, or interpretation of data; in the writing of the manuscript, or in the decision to publish the results.

\section{References}

1. Lorenzini, M.; Kim, W.; Momi, E.D.; Ajoudani, A. A New Overloading Fatigue Model for Ergonomic Risk Assessment with Application to Human-Robot Collaboration. In Proceedings of the 2019 International Conference on Robotics and Automation, ICRA 2019, Montréal, QC, Canada, 20-24 May 2019; Institute of Electrical and Electronics Engineers Inc., HRI2 Lab, Istituto Italiano di Tecnologia: Genoa, Italy, 2019; pp. 1962-1968. [CrossRef]

2. Maurice, P.; Padois, V.; Measson, Y.; Bidaud, P. Human-Oriented Design of Collaborative Robots. Int. J. Ind. Ergon. 2017, 57, 88-102. [CrossRef]

3. Canjuga, M.; Hammig, O.; Bauer, G.F.; Laubli, T. Correlates of Short- and Long-Term Absence Due to Musculoskeletal Disorders. Occup. Med. 2010, 60, 358-361. [CrossRef] [PubMed]

4. El Makrini, I.; Merckaert, K.; De Winter, J.; Lefeber, D.; Vanderborght, B. Task Allocation for Improved Ergonomics in HumanRobot Collaborative Assembly. Interact. Stud. Soc. Behav. Commun. Biol. Artif. Syst. 2019, 20, 102-133. [CrossRef]

5. Ranavolo, A.; Ajoudani, A.; Cherubini, A.; Bianchi, M.; Fritzsche, L.; Iavicoli, S.; Sartori, M.; Silvetti, A.; Vanderborght, B.; Varrecchia, T.; et al. The Sensor-Based Biomechanical Risk Assessment at the Base of the Need for Revising of Standards for Human Ergonomics. Sensors 2020, 20, 5750. [CrossRef]

6. Parra, P.S.; Calleros, O.L.; Ramirez-Serrano, A. Human-Robot Collaboration Systems: Components and Applications. Int. Conf. Control. Dyn. Syst. Robot. 2020, 150, 1-9. [CrossRef]

7. Kim, W.; Lorenzini, M.; Balatti, P.; Nguyen, P.D.H.; Pattacini, U.; Tikhanoff, V.; Peternel, L.; Fantacci, C.; Natale, L.; Metta, G.; et al Adaptable Workstations for Human-Robot Collaboration: A Reconfigurable Framework for Improving Worker Ergonomics and Productivity. IEEE Robot. Autom. Mag. 2019, 26, 14-26. [CrossRef]

8. Pearce, M.; Mutlu, B.; Shah, J.; Radwin, R. Optimizing Makespan and Ergonomics in Integrating Collaborative Robots into Manufacturing Processes. IEEE Trans. Autom. Sci. Eng. 2018, 15, 1772-1784. [CrossRef]

9. Gualtieri, L.; Rauch, E.; Vidoni, R. Emerging Research Fields in Safety and Ergonomics in Industrial Collaborative Robotics: A Systematic Literature Review. Robot. Comput. Integr. Manuf. 2021, 67, 101998. [CrossRef]

10. Charalambous, G.; Fletcher, S.; Webb, P. The Development of a Scale to Evaluate Trust in Industrial Human-Robot Collaboration. Int. J. Soc. Robot. 2016, 8, 193-209. [CrossRef]

11. Brun, L.; Wioland, L. Prevention of Occupational Risks Related to the Human-Robot Collaboration. Adv. Intell. Syst. Comput. 2021, 1253, 441-446. [CrossRef]

12. Kim, W.; Peternel, L.; Lorenzini, M.; Babič, J.; Ajoudani, A. A Human-Robot Collaboration Framework for Improving Ergonomics During Dexterous Operation of Power Tools. Robot. Comput. Integr. Manuf. 2021, 68. [CrossRef]

13. Hopko, S.K.; Khurana, R.; Mehta, R.K.; Pagilla, P.R. Effect of Cognitive Fatigue, Operator Sex, and Robot Assistance on Task Performance Metrics, Workload, and Situation Awareness in Human-Robot Collaboration. IEEE Robot. Autom. Lett. 2021, 6, 3049-3056. [CrossRef]

14. Colim, A.; Faria, C.; Cunha, J.; Oliveira, J.; Sousa, N.; Rocha, L.A. Physical Ergonomic Improvement and Safe Design of an Assembly Workstation through Collaborative Robotics. Safety 2021, 7, 14. [CrossRef]

15. Salunkhe, O.; Stensöta, O.; Åkerman, M.; Berglund, Å.F.; Alveflo, P.A. Assembly 4.0: Wheel Hub Nut Assembly Using a Cobot. IFAC Pap. 2019, 52, 1632-1637. [CrossRef]

16. Pini, F.; Ansaloni, M.; Leali, F. Evaluation of Operator Relief for an Effective Design of HRC Workcells. In Proceedings of the 21st IEEE International Conference on Emerging Technologies and Factory Automation, ETFA 2016, Berlin, Germany, 6-9 September 2016; Institute of Electrical and Electronics Engineers Inc.: Department of Engineering “Enzo Ferrari", University of Modena and Reggio Emilia: Vivarelli, Italy, 2016. [CrossRef]

17. Cherubini, A.; Passama, R.; Crosnier, A.; Lasnier, A.; Fraisse, P. Collaborative Manufacturing with Physical Human-Robot Interaction. Robot. Comput. Integr. Manuf. 2016, 40, 1-13. [CrossRef] 
18. Shafti, A.; Ataka, A.; Lazpita, B.U.; Shiva, A.; Wurdemann, H.A.; Althoefer, K. Real-Time Robot-Assisted Ergonomics. In Proceedings of the 2019 International Conference on Robotics and Automation (ICRA), Montreal, QC, Canada, 20-24 May 2019; pp. $1975-1981$.

19. Colim, A.; Morgado, R.; Carneiro, P.; Costa, N.; Faria, C.; Sousa, N.; Rocha, L.A.; Arezes, P. Lean Manufacturing and Ergonomics Integration: Defining Productivity and Wellbeing Indicators in a Human-Robot Workstation. Sustainability 2021, $13,1931$. [CrossRef]

20. Villani, V.; Pini, F.; Leali, F.; Secchi, C. Survey on Human-Robot Collaboration in Industrial Settings: Safety, Intuitive Interfaces and Applications. Mechatronics 2018, 55, 248-266. [CrossRef]

21. Müller, R.; Vette, M.; Scholer, M. Robot Workmate: A Trustworthy Coworker for the Continuous Automotive Assembly Line and Its Implementation. Procedia CIRP 2016, 44, 263-268. [CrossRef]

22. Dimitropoulos, N.; Togias, T.; Zacharaki, N.; Michalos, G.; Makris, S. Seamless Human-Robot Collaborative Assembly Using Artificial Intelligence and Wearable Devices. Appl. Sci. 2021, 11, 5699. [CrossRef]

23. Vega-Barbas, M.; Diaz-Olivares, J.A.; Lu, K.; Forsman, M.; Seoane, F.; Abtahi, F. P-Ergonomics Platform: Toward Precise, Pervasive, and Personalized Ergonomics Using Wearable Sensors and Edge Computing. Sensors 2019, 19, 1225. [CrossRef] [PubMed]

24. Tranfield, D.; Denyer, D.; Palminder, S. Towards a Methodology for Developing Evidence-Informed Management Knowledge by Means of Systematic Review. Br. J. Manag. 2003, 14, 207-222. [CrossRef]

25. Moher, D.; Liberati, A.; Tetzlaff, J.T.; Altman, D.G. Preferred Reporting Items for Systematic Reviews and Meta-Analyses: The PRISMA Statement. PLoS Med. 2009, 6, 339. [CrossRef] [PubMed]

26. Duarte, J.; Torres Marques, A.; Santos Baptista, J. Occupational Accidents Related to Heavy Machinery: A Systematic Review. Safety 2021, 7, 21. [CrossRef]

27. Palomba, I.; Gualtieri, L.; Rojas, R.; Rauch, E.; Vidoni, R.; Ghedin, A. Mechatronic Re-Design of a Manual Assembly Workstation into a Collaborative One for Wire Harness Assemblies. Robotics 2021, 10, 43. [CrossRef]

28. Gualtieri, L.; Palomba, I.; Merati, F.A.; Rauch, E.; Vidoni, R. Design of Human-Centered Collaborative Assembly Workstations for the Improvement of Operators' Physical Ergonomics and Production Efficiency: A Case Study. Sustainbility 2020, $12,3606$. [CrossRef]

29. Zanchettin, A.M.; Lotano, E.; Rocco, P. Collaborative Robot Assistant for the Ergonomic Manipulation of Cumbersome Objects. IEEE Int. Conf. Intell. Robot. Syst. 2019, 6729-6734. [CrossRef]

30. Heydaryan, S.; Bedolla, J.S.; Belingardi, G. Safety Design and Development of a Human-Robot Collaboration Assembly Process in the Automotive Industry. Appl. Sci. 2018, 8, 344. [CrossRef]

31. Maurice, P.; Measson, Y.; Padois, V.; Bidaud, P. Assessment of Physical Exposure to Musculoskeletal Risks in Collaborative Robotics Using Dynamic Simulation. CISM Int. Cent. Mech. Sci. Courses Lect. 2013, 544, 325-332. [CrossRef]

32. Rossato, C.; Pluchino, P.; Cellini, N.; Jacucci, G.; Spagnolli, A.; Gamberini, L. Facing with Collaborative Robots: The Subjective Experience in Senior and Younger Workers. Cyberpsychol. Behav. Soc. Netw. 2021, 24, 349-356. [CrossRef]

33. Prati, E.; Peruzzini, M.; Pellicciari, M.; Raffaeli, R. How to Include User EXperience in the Design of Human-Robot Interaction. Robot. Comput. Integr. Manuf. 2021, 68, 102072. [CrossRef]

34. Sadrfaridpour, B.; Saeidi, H.; Wang, Y. An Integrated Framework for Human-Robot Collaborative Assembly in Hybrid Manufacturing Cells. In Proceedings of the 2016 IEEE International Conference on Automation Science and Engineering, CASE 2016, Fort Worth, TX, USA, 21-25 August 2016; IEEE Computer Society: Department of Mechanical Engineering, Clemson University: Clemson, SC, USA, 2016; pp. 462-467. [CrossRef]

35. Charalambous, G.; Fletcher, S.; Webb, P. Development of a Human Factors Roadmap for the Successful Implementation of Industrial Human-Robot Collaboration. In Proceedings of the International Conference on Human Aspects of Advanced Manufacturing, HAAMAHA 2016, Orlando, FL, USA, 27-31 July 2016; Springer: London, UK, 2016; pp. 195-206. [CrossRef]

36. Liau, Y.Y.; Ryu, K. Task Allocation in Human-Robot Collaboration (HRC) Based on Task Characteristics and Agent Capability for Mold Assembly. Procedia Manuf. 2020, 51, 179-186. [CrossRef]

37. Ottogalli, K.; Rosquete, D.; Rojo, J.; Amundarain, A.; María Rodríguez, J.; Borro, D. Virtual Reality Simulation of Human-Robot Coexistence for an Aircraft Final Assembly Line: Process Evaluation and Ergonomics Assessment. Int. J. Comput. Integr. Manuf. 2021, 34, 975-995. [CrossRef]

38. Lambrechts, W.; Klaver, J.S.; Koudijzer, L.; Semeijn, J. Human Factors Influencing the Implementation of Cobots in High Volume Distribution Centres. Logistics 2021, 5, 32. [CrossRef]

39. Beck, S.; Bergenholtz, C.; Bogers, M.; Brasseur, T.M.; Conradsen, M.L.; Di Marco, D.; Distel, A.P.; Dobusch, L.; Dörler, D.; Effert, A.; et al. The Open Innovation in Science Research Field: A Collaborative Conceptualisation Approach. Ind. Innov. 2020, 1-50. [CrossRef]

40. Kim, W.; Lee, J.; Peternel, L.; Tsagarakis, N.; Ajoudani, A. Anticipatory Robot Assistance for the Prevention of Human Static Joint Overloading in Human-Robot Collaboration. IEEE Robot. Autom. Lett. 2018, 3, 68-75. [CrossRef]

41. International Ergonomics Association. What is Ergonomics? Available online: https://iea.cc/what-is-ergonomics/ (accessed on 3 June 2021). 
42. David, G.C. Ergonomic Methods for Assessing Exposure to Risk Factors for Work-Related Musculoskeletal Disorders. Occup. Med. 2005, 55, 190-199. [CrossRef]

43. Colim, A.; Faria, C.; Braga, A.C.; Sousa, N.; Carneiro, P.; Costa, N.; Arezes, P. Towards an Ergonomic Assessment Framework for Industrial Assembly Workstations-A Case Study. Appl. Sci. 2020, 10, 3048. [CrossRef] 